\title{
GiRESUN iL MERKEZINDEKI INTIHAR GiRIŞiMLERININ SOSYODEMOGRAFIK INCELEMESI
}

\author{
F. Üstüner Top ${ }^{\star}$, H. Sarı ${ }^{\star}$ F. Kostakoğlü* , S. Başkan*, E. Aydın Pekdemir
}

\section{ÖZET}

Amaç: Çalışmanın amacı; 2007 yılında intihar girişimiyle Giresun ili Prof. Dr. A.lihan Özdemir Devlet Hastanesi ve Kale Devlet Hastanesi Acil Servisi'ne getirilen hastaların sosyodemografik özelliklerini saptamaktır. Yöntem: Çalışma 2007 yılında Giresun ili Devlet Hastaneleri'nin acil kliniklerine intihar girișimi nedeni ile başvuran hastalara ilişkin kayıtlar incelenerek yapılmıştır. Bulgular: Bireylerin \%70.7'sinin kadın,\%29.3'ünün erkek olduğu saptanmıştır. İntihar girişimi yöntemi incelendiğinde en sık kullanılan yöntemin \%88.8 ile aşırı dozda ilaç alımı olduğu bulunmuştur. İntihar girişiminde bulunanların \%55.4'ü ailevi sorunlar nedeniyle girişimi gerçekleştirdiğini belirtmiştir. Sonuç: Kadınlar erkeklere kıyasla daha fazla intihar girişiminde bulunmaya yatkındır. İntihar girişimi ile ilgili ülke çapında sosyo-ekonomik durum ve psikiyatrik tanı konusunda düzenli bir kayıt sistemine gereksinim vardır.

Anahtar Sözcük: İntihar girişimi, risk faktörleri, sosyodemografik özellik.

\footnotetext{
* Öğr. Gör., Giresun Üniversitesi, Sağlık Yüksekokulu.

** Öğr. Hemş, Giresun Üniversitesi, Sağlık Yüksekokulu.
}

The Sociodemographic Analysis of Suicide Attempts In the City Centre of Giresun

\section{SUMMARY}

Objective: The aim of this study is to determine the sociodemographic characteristics of the patients were removed to emergency services of Prof. Dr. A. İlhan Özdemir State Hospital and Kale State Hospital because of attempted suicide in Giresun in 2007. Method: The study were conducted by analysing of data about patients who were removed to the emergency services of the State Hospitals in Giresun because of attempted suicide in 2007. Results: It is confirmed $70.7 \%$ of those who have attempted suicide are female and $29.3 \%$ of them are male. When the methods of the suicides are examined, the most common one is to take overdose medicine in $88 \% 55.4 \%$ of the patients implied that they attempted suicide because of family problems Conlusion: When compared with men, women are more prone to making attempted suicide. We can say that a regular recording system is essential for socioeconomic situations and psychiatric diagnosis 
of patients who were attempted suicide around the country.

Key Words: Suicide attempt, risk factors, sociodemographic characteristic.

\section{Giriş}

İntihar, insanın öz benliğine yönelmiş bir saldırganlık ve yok etme eylemi olup, bireyin istemli olarak yaşamına son vermesidir (Deniz ve ark 2001). Ölümle sonuçlanan intiharlar "intihar eylemi", sonuçlanmayanlar ise "intihar girişimi" olarak adlandırılır (Alper ve ark 2001). Kadınlar erkeklerin 3 katı fazla intihar girişiminde bulunurken erkekler 3 kat daha fazla intihar eylemini gerçekleştirirler (Halgin ve ark 2006). Kadınlar "yardım çığlığı" dediğimiz (daha çok ilaç alımıyla) intihar girişiminde bulunurken, erkekler daha kesin ölüme götürecek yardımı imkansız kılan yollarla (ateşli silah, yüksekten atlama, suda boğulma vb.) intihar eylemini gerçekleştirmektedir (Nolen ve ark 2004).

İntihar girişimi tarihte önemli bir sorun olarak saptanıp birçok araştırmacı tarafından ele alınıp incelenmiştir. İntihar girişimi dünyada önemli bir halk sağlığı sorunudur. Bütün ölümlerin yaklaşık \% 0.9'u intihar sonucu gerçekleşmekte olup; her gün dünyada yaklaşık 1000 kişi intihar sonucu yaşamını yitirmektedir. Macaristan, Almanya, Avusturya, Danimarka ve Japonya' da yüksek; Mısır, Meksika, Yunanistan ve İspanya'da ise düşüktür. ABD, Kanada ve Ingiltere'deki oranlar bu iki kutubun arasındadır. Mesela Amerika'da her 100 bin kişiden 12'si intihar girişiminde bulunup her sene 30 bin kişi intihar eylemini gerçekleştirmektedir (Emery ve Thomas 2000).

İntihar girişim oranlarındaki ülkeler arası farklılık intihara yönelik kültürel ve dini normlarla ilgilidir. İslami toplumlarda intihar dini yönden yasak olduğu, intihar edenlerin cenaze namazlarının kılınmadığı vb. anlayış nedeniyle intihar hızı düşükken, Japon geleneğinde Harakiri yapılarak intihar kahramanca bir davranış olarak algılanmakta ve bu durum Japonya'daki intihar girişim hızını yükseltmektedir. Bu olay aynı zamanda kişileri intihara özendirmektedir (Nolen ve ark 2004).

İstatistikler incelendiğinde intihar oranlarında Dünya ortalaması yüzbinde 13 iken Türkiye'de ortalama yüzbinde 3.3'dür. Devlet İstatistik Enstitüsü'nün (DIE) 2002 verileri göre 2301 kişi intihar ederek yaşamına son vermiştir. Bunların \%55'i 15-34 yaş grubundadır. İtihar hızlarında erkeklerin kadınlara oranı 3/2'dir. Türkiye'nin coğrafik bölgelerine bakıldığında ise Ege Bölgesi yüzbinde 5.28 ile en yüksek intihar hızına sahipken araştırmamızı yaptığımız Giresun ilinin de bulunduğu Karadeniz Bölgesi yüzbinde 2.03 ile en düşük intihar hızına sahiptir.

Ülkemizde, verilere göre intihar hızı yıldan yıla artmakta ve giderek büyümekte olan bir sorun haline gelmektedir. İtihar girişiminin sebeplerinin, risk faktörlerinin iyi anlaşılması erken müdahaleyi ve olası intihar girişimlerinin önlenmesini sağlamaktadır (Ertemir ve ark 2003). Bu çalışmayla 2007 yılında intihar girişimiyle Giresun ili Prof. Dr. A.Illhan Özdemir Devlet Hastanesi ve Kale Devlet Hastanesi Acil Servisi'ne başvuran hastaların sosyodemografik özelliklerinin saptanması amaçlanmıştır.

\section{YÖNTEM VE GEREÇLER}

Araştırma Giresun ili genelinde 01.01.2007-01.01.2008 tarihleri arasında intihar girişimiyle acil polikliniğe başvuran toplam 116 bireyi kapsamaktadır. Evrenin tamamı örneklem grubuna alınmıştır.

Veriler Sağlık Müdürlüğü'den izin alınarak incelenen intihar girişim formlarının geriye dönük olarak incelenmesiyle elde edilmiştir. İntihar girişim formu; her bireyde sosyodemografik bilgiler, intihara güdüleyen yaşam olayı, intihar girişimi yöntemi, intihar ayı ve günü, önceden intihar girişimi, kendinde ve ailede psikiyatrik hastalık, ailede intihar girişimi, geçirdiği fiziksel hastalık hakkında bilgilerin araştııılığı bir formdur. Formlar acil kliniğinde çalışan sağlık per- 
sonelleri tarafından, hastaların stabilleştiği dönemde sözlü onamları alınarak doldurulmuştur.

Veriler SPSS for Windows 10.0 veri tabanı programına aktarılarak öncelikle tanımlayıcı istatistiksel yapılmıştır. Ardından önceden intihar girişiminde bulunmayla diğer değişkenler arasındaki ilişkinin araştırılmasında ki-kare testi kullanılmıştır.

\section{BULGULAR}

Araştırmamızda bireylerin \%70.7'sinin $(n=82)$ kadın, \%29.3'ünün $(n=34)$ erkek, \%34.1'inin ( $n=28)$ öğrenci, \%49.1'inin( $n=55)$ ilköğretim mezunu olduğu saptanmıştır. Bireylerin \%53.5'inin ( $n=55)$ 15-24 yaş aralığında olduğu bulunmuştur (Tablo 1).

Kullanılan yöntemlere bakıldığında; en sık \%88.8 ( $n=103$ ) ile aşırı dozda ilaç alımı bulunmuştur. Bunu \%6.9 ( $n=8)$ ile kesici alet ve \%1.7 $(n=2)$ ile suya atlama izlemektedir (Tablo 2).

Araştırmamızda kadınların \%93.9'u erkeklerin \%76.5'i intihar girişim yöntemi olarak ilaçtoksik madde alımını kullanmıştır. Kesici alet ve diğer yöntemlerin kullanımı kadınlarda \%6.1 iken erkeklerde bu oran \%23.5 olarak bulunmuştur. Hem kadın ve hem de erkeklerde ilaçtoksik madde alımı yöntemi yaygın bulunurken; kesici alet ve diğer yöntemin kullanımı erkeklerde kadınlara oranla daha yaygın bulunmaktadır. Cinsiyete göre kullanılan intihar girişim yöntemi incelendiğinde aradaki fark istatistiksel olarak da anlamlı bulunmuştur $(p<0.05$, Tablo 3).

Aylara göre intihar girişimi gerçekleştirme sıklığı incelendiğinde en sık \%16.4 ( $n=19)$ ile Mayıs ayında, ikinci sırada \%15.5 ( $n=18)$ ile Haziran ayında olduğu saptanmıştır. En az ise \%2.6 ( $n=3)$ ile Ağustos ayında intihar girişimi saptanmıştır. Bunun yanında en az intihar girişimlerinin sonbahar mevsiminde olduğu görülmüştür (Grafik 1).
İntihar girişim saatleri incelendiğinde en sık \%36.2 ( $n=34)$ ile 18-24 saat aralığında görülmüştür. İntihar girişiminin en az ise \%12.1 ( $n=14)$ ile 24-06 saat aralığında görüldüğü saptanmıştır.

Intihar girişiminde bulunan bireylerin \%42.9'unun 18-24 saat aralığında, \%22'sinin 12-18 saat aralığında, \%20'sinin 6-12 saat aralığında, \%15.1'nin 24-06 saat aralığında acil servise başvurduğu saptanmıştır.

İlaç-toksik madde alarak intihar girişiminde bulunan bireylerin \%93.7'si $(n=74)$ girişimde bulunduktan sonraki 30 dakika içinde acile başvurmuştur. Kesici alet ve diğer yöntemlerle intihar girişiminde bulunanların \%55.6'sı $(n=5)$ ise ilk yarım saat içinde acile başvurmuştur. Ilaç alan kişilerin ilk 30 dakika içinde acil servise başvurma oranları kesici alet kullananlara göre daha yüksektir. Bireylerin intihar girişimi için kullandıkları yöntem ile acil kliniğe başvurma zamanı arasındaki fark istatistiksel olarak anlamlı bulunmuştur $(p<0.05)$.

İntihar girişimini güdüleyen yaşam olayı bireylerin \%5.2'sinde $(n=6)$ yok iken, $\% 55.4$ 'ünde $(n=60)$ ailevi sorunlar (aile içi şiddet, ebeveyn çatışmalar vb.), \%12.7'sinde $(n=14)$ karşı cinsle sorunlar en sık rastlanan intihar nedenleri olarak saptanmıştır.

İntihar girişim nedenlerinin yaşa göre dağılımına bakıldığında tüm yaş aralıklarında ailevi sorunlar öne çıkmaktadır (Tablo 4).

Araştırmamızda bireylerin \%83.2'sinin daha önce intihar girişiminde bulunmadığı, \%16.8'inin daha önce girişimde bulunduğu saptanmıştır. İntihar girişim formlarının eksik doldurulması nedeniyle bireylere ait veriler tam saptanamamıştır. Bireylerin daha önceki intihar girişim öyküleri ile cinsiyetleri arasında istatistiksel olarak belirgin bir fark bulunamamıştır $(p>0.05)$. 
Tablo 1: İntihar Girişiminde Bulunan Bireylerin Sosyodemografik Özeliklerinin Dağılımı.

\begin{tabular}{llcc}
\hline & & $\mathrm{n}$ & $\%$ \\
\hline Cinsiyet & Kadın & & \\
& Erkek & 82 & 70.7 \\
& & 34 & 29.3 \\
\hline Eğitim Düzeyi & Okur-yazar değil & 2 & \\
& Okur-yazar & 1 & 1.8 \\
& İlköğretim & 55 & 0.9 \\
& Lise & 43 & 39.1 \\
& Yüksekokul & 9 & 8 \\
\hline Medeni Durumu & & & \\
& Hiç evlenmemiş & 63 & 58.9 \\
& Evli & 40 & 37.4 \\
& Boşanmış & 2 & 1.9 \\
& Dul & 2 & 1.9 \\
\hline Meslek & & & \\
& Evv Kadını & 24 & 29.3 \\
& Öğrenci & 28 & 34.1 \\
& Memur & 7 & 8.5 \\
& Serbest Meslek & 21 & 25.6 \\
& İşçi & 1 & 0.9 \\
& & &
\end{tabular}

Tablo 2: İntihar Girişiminde Kullanılan Yöntemlerin Dağılımı.

\begin{tabular}{lrr}
\hline İntihar Girişim Yöntemi & $\mathrm{n}$ & $\%$ \\
\hline İlaç-Toksik Madde & 103 & 88.8 \\
Kesici Alet & 8 & 6.9 \\
Suya Atlama & 2 & 1.7 \\
Yüksekten Atlama & 1 & 0.9 \\
Kendini Asma & 1 & 0.9 \\
Yakma & 1 & 0.9 \\
\hline Toplam & 116 & 100
\end{tabular}

Tablo 3: Cinsiyete Göre Kullanılan İntihar Yöntemlerinin Dağılımı.

\begin{tabular}{|c|c|c|c|c|}
\hline \multirow{3}{*}{ Cinsiyet } & \multicolumn{4}{|c|}{ İntihar Girişim Yöntemi } \\
\hline & \multicolumn{2}{|c|}{ İlaç-Toksik Madde } & \multicolumn{2}{|c|}{ Kesici Alet ve Diğerleri } \\
\hline & $\mathrm{n}$ & $\%$ & $\mathrm{n}$ & $\%$ \\
\hline Kadın & 77 & 93.9 & 5 & 6.1 \\
\hline Erkek & 26 & 76.5 & 8 & 23.5 \\
\hline Toplam & 103 & 88.8 & 13 & 11.2 \\
\hline
\end{tabular}


$\begin{array}{llll}K & R & i & Z\end{array}$

Tablo 4: İntihar Nedenlerinin Yaşa Göre Dağılımı.

\begin{tabular}{|c|c|c|c|c|c|c|c|c|c|c|}
\hline \multirow{3}{*}{ İntihar Nedeni } & \multicolumn{10}{|c|}{ Yaş Aralığı } \\
\hline & \multicolumn{2}{|c|}{$15-24$} & \multicolumn{2}{|c|}{$25-34$} & \multicolumn{2}{|c|}{$35-49$} & \multicolumn{2}{|c|}{$50-64$} & \multicolumn{2}{|c|}{ Toplam } \\
\hline & $\mathrm{n}$ & $\%$ & $\mathrm{n}$ & $\%$ & $\mathrm{n}$ & $\%$ & $\mathrm{n}$ & $\%$ & $\mathrm{n}$ & $\%$ \\
\hline Ailevi Sorunlar & 32 & 53.3 & 16 & 26.7 & 12 & 20 & -- & -- & 60 & 100 \\
\hline Karşı Cinsle Sorunlar & 16 & 69.6 & 5 & 21.8 & 1 & 4.3 & 1 & 4.3 & 23 & 100 \\
\hline $\begin{array}{l}\text { Hastalık (süreğen, } \\
\text { ruhsal hastalık) }\end{array}$ & 3 & 23.1 & 4 & 30.7 & 4 & 30.7 & 2 & 15.3 & 13 & 100 \\
\hline $\begin{array}{l}\text { Okulla İlgili Sorunlar } \\
\text { (sınav kaygısı) }\end{array}$ & 4 & 100 & -- & -- & -- & -- & -- & -- & 4 & 100 \\
\hline Ekonomik Sorunlar & 2 & 25 & 5 & 25 & 1 & 12.5 & -- & -- & 8 & 100 \\
\hline Toplam & 57 & 52.7 & 30 & 27.8 & 18 & 16.7 & 3 & 2.8 & 108 & 100 \\
\hline
\end{tabular}

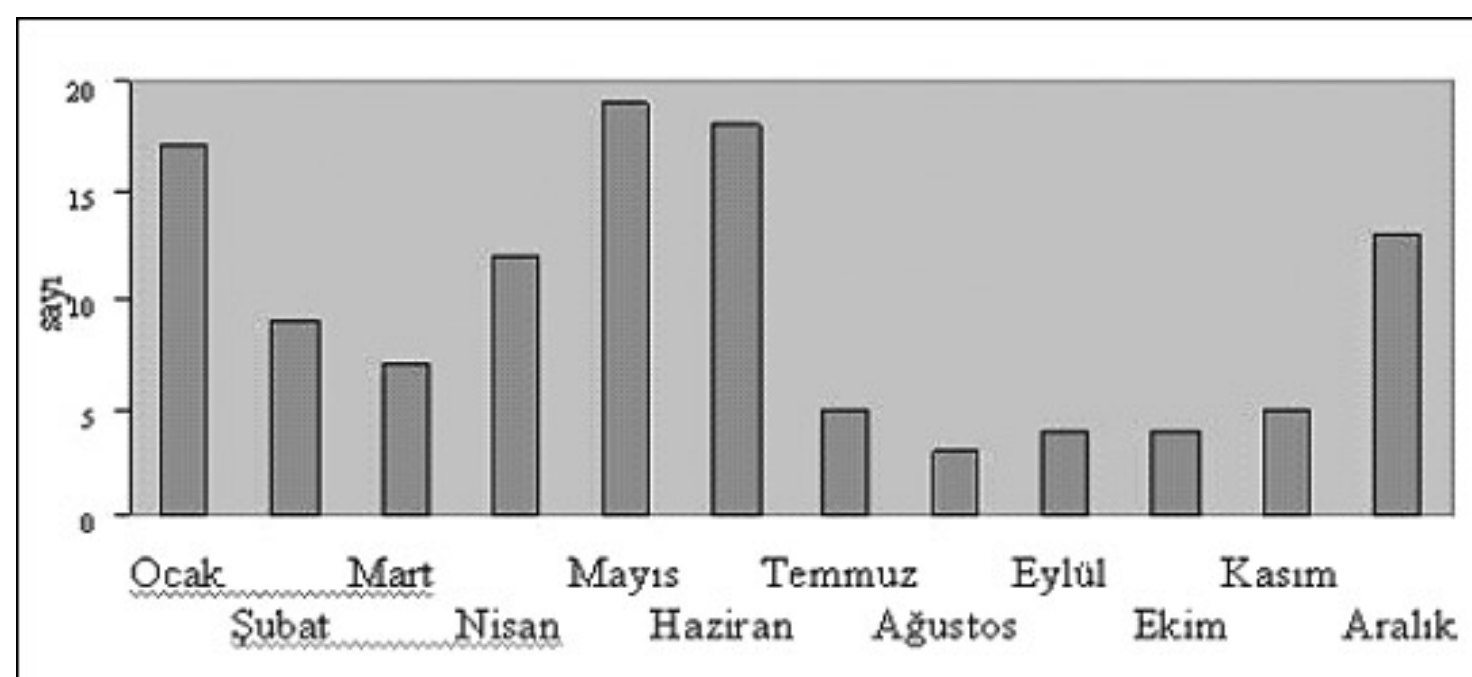

Grafik 1: İntihar Girişiminin Aylara Göre Dağılımı. 


\section{TARTIŞMA}

Araştırmamızda kadınların daha fazla intihar girişiminde bulunduğu saptanmıştır. Oktik ve arkadaşlarının Muğla ili genelinde intihar ve intihar girişimi olan bireyleri değerlendirdikleri çalışmada intihar girişiminin \%72'sinin kadın, \%28'inin erkek olduğunu bildirmişlerdir (Oktik ve ark. 2003). Benzer bir çalışma da kadınların erkeklere göre daha fazla intihar girişiminde bulunduğu bilgisini doğrulamaktadır (Howard ve Sudak 2004).

İntihar girişim oranları ile yaş artışı arasındaki negatif ilişki her iki cins için de bilinmektedir (Kaplan ve Sadok 2000). Araştırmamızda 15-24 yaş grubu 55 kişi ile ilk sıradadır. Genel bir hastanede intihar girişimlerinin değerlendirildiği araștırmada ise 25 ve altı yaş grubun 1635 kişi ile ilk sırada olduğu saptanmıştır (Dilbaz ve ark. 2005). Batman ilindeki intiharların incelendiği bir araştırmada en fazla intihar oranı 15-24 yaş grubunda görülmüştür (Sayıl 2004). Devrimci ve Sayıl tarafından 2003'te yapılan çalışmada Avrupa ülkelerine göre daha düşük olmakla birlikte intihar girişiminde bulunanların büyük çoğunluğunu Avrupa ülkelerinde olduğu gibi 1519 yaş arasındaki gençler olduğu saptanmıştır (Devrimci ve Sayıl 2003).

Araştırmamızda medeni durum incelendiğinde intihar girişiminde bulunanlar içerisinde bekarların oranı evlilerden yüksek bulunmuştur. Gençlerin intihar girişimlerinin incelendiği başka bir araştırmada da intihar girişiminde bulunanların \%67'sinin bekar, \%32'sinin evli olduğu bulunmuştur (Ertemir ve ark. 2003). Bu bulgular benzer çalışmalarda yalnız yaşayanlarda intihar oranının evlilerden iki kat daha fazla olduğu bilgisini doğrulamaktadır.

Araştırmamızda her iki cins için en çok kullanılan yöntemin yüksek doz ilaç alımı olduğu saptanmıştır. Başka bir çalışmada da intihar girişimi için her iki cinsiyet için en çok kullanılan yöntem yüksek doz ilaç alımı, kadınlar için ikin- ci sırada diğer kimyasalların ağız yoluyla alımı, erkekler için yüksekten atlama saptanmıştır (Devrimci ve Sayıl 2003). Avrupa'daki intihar girişimlerinin epidemiyolojisinin araştırıldığı araştırmada bölgeler arası yöntemler farklılık gösterse de genelde en yaygın yöntem yüksek dozda ilaç alımı olduğu saptanmıştır (Brahe 2001). İlaç alarak yaşama son vermenin acı vermeyeceği inancı nedeniyle daha çok tercih edildiği düşünülmektedir. İntihar girişimlerinde ilaç alımının sık görülmesinin başka bir nedeni ise bu vakalarda; yardım arama, girişim yoluyla tehdit gibi davranışların ön planda olması düşünülebilir.

Yapılan araştırmalar genellikle intihar girişimlerinin 20-24 saatleri arasında yani günün 2.yarısında gerçekleştiğini göstermektedir (Dilbaz ve ark 2005). Araştırmamızda en sık girişim 18-24 saatleri arasında olup bu zaman diliminde intihar girişiminde bulunanlar tüm olguların \%36.2'sini oluşturmaktadır. Sabaha karşı ve gündüz saatlerinde ise intihar oranının düşük olduğu saptanmıştır. Özellikle herkesin evde olduğu saatlerde tepe yapması girişimin yardım çağrısı olması şeklinde yorumlanabilir.

İntihar girişimleri dünyanın her iki yarım küresinde ilkbahar ve yaz başında en yüksek oranda görülür. Yapılan bir çalışmada intihar girişimi ile mevsimler arasında ilişki bulunmadığı, sadece ilkbahar ve sonbaharda hafif bir artışın olduğu ve yaygın kanının aksine tatil dönemlerinde artış olmadığı görülmektedir (Kaplan ve Sadok 2004). Araştırmamızda Mayıs ayı başta olmak üzere ilkbahar ve yaz aylarında intihar girişiminin daha fazla olması benzer çalışma sonuçları ile uyum göstermektedir. Celal Bayar Üniversitesi Hastanesi'nde yapılan bir araştırmada Nisan ayı başta olmak üzere bahar aylarında intihar girişimlerinin daha fazla olduğu saptanmıştır (Deveci ve ark. 2005).

Formlardaki bilgilerin tam olarak alınmamış olması araşıımanın sınırılığını oluşturmuştur. Intihar girişiminde bulunanlarda ruhsal bozuklukların incelendiği bir araştırmada intihar 
girişiminde bulunan bireylerin \%14'ünün psikiyatrik tanısının olmadığı saptanmıștır. Psikiyatrik tanısı olan bireylerde ise \%45.6 ile majör depresif bozukluk ilk sırada yer almaktadır (Deveci ve ark.2005). Araştırmamızda acil polikliniğinde verilerin eksik tutulması ve bunun sonucunda bu verilere ulaşamamamız nedeniyle bu bulgular saptanamamıştır.

\section{SONUÇ}

Araştırmamızda risk grubu olarak 15-24 yaş arası gençler ve risk etmeni olarak ailevi ve karşı cinsle ilgili sorunlar öne çıkmaktadır. İntihar girişimi en fazla örgencilerde görülmektedir. $\mathrm{Bu}$ gruptaki intihar girişim olgularını en aza indirmek için arkadaşlar, öğretmenler ve diğer eğitimcilerle işbirliği yapılması gerekmektedir. Ailevi sorunların risk etmeni olarak en aza indirilmesi için aile bağlarının güçlenmesi ve aile içi eğitim çalışmalarına ağırlık verilmesi gerekmektedir.

Araştırmamızdaki en önemli sınırlılık hastane kayıtlarının düzenli tutulmamış olmasıdır.
Bu konuyla ilgili, hekimler ve diğer sağlık çalışanlarının eğitilmesi, erken tanı, tedavi ve gereğinde uygun kurumlara yönlendirme konusunda bilgilendirilmesi önem kazanmaktadır.

Ülkemizde intihar girişimi ile ilgili gerek hastane gerekse polis kayıtlarının dini, yasal, toplumsal nedenlerden dolayı sağlıklı tutulmaması ile ilgili zorluklar yaşanmaktadır. Bu doğru verilerin elde edilmesini, bu önemli sorunun boyutlarının gün ışığına çıkmasını engelleyebilmektedir. Bu nedenle tüm epidemiyolojik özellikler ve faktörler her ülke için sağlıklı olarak elde edilmeli ve intihar ve intihar girişimlerini önlemeye yönelik geliştirilecek programların oluşturulmasına öncülük etmelidir.

Sonuç olarak; intihar girişimi ülkemizde giderek artan bir halk ve ruh sağlığı sorunu olmaktadır. Durum ile ilgili olarak risk etmenlerini değerlendirmek, önleyici çalışmalarda bulunmak önemli gözükmektedir. 


\section{KAYNAKLAR}

Alper Y, Bayraktar E, Karaçam Ö (2001) Herkes İçin Psikiyatri. Gendaş Kültür Yayınları. Birinci Basım, s.329-339.

Brahe B (2001) The Epidemiyology of Suicide Attemps In Europe. Kriz Dergisi, 9(1):19-32

Carson R, Butcher J, Mineka S (2002) Fundamentals of Abnormal Pshychology and Modern Life. A Pearson Education, s.226-235.

Deniz I, Ersöz A, İldeş N, Türkaslan N (2001) 1995-2000 Yılları Resmi Kayıtlarından Batman'da Gerçekleşen İntihar ve İntihar Girişimleri Üzerine Bir İnceleme. Aile ve Toplum Dergisi, 1(4):27-48.

Deveci A, Aydemir Ö, Mızrak S (2005) İntihar Girişiminde Bulunanlarda Sosyodemografik Özellikler, Stres Etmenleri ve Ruhsal Bozukluklar. Kriz Dergisi, 13(1): 1-9.

Devrimci-Özgüven H, ve Sayıl I (2003) Suicide Attempts in Turkey: Results of the WHO/EURO Multicentre Study of Suicidal Behavior. Can J Psychiatry, 48(5):324-329.

Dilbaz N, Şengül C, Çetin M ve ark (2005) Genel Bir Hastanede İntihar Girişimlerinin Değerlendirilmesi. Kriz Dergisi, 13(2):1-10.
Emery R, Thomas F (2000) Essentials of Abnormal Psyhology. Prentice- Hall International Limited, s.144-150.

Ertemir D, Ertemir M (2003) Gençlerin İtihar Girişimlerinin Özellikleri. Düşünen Adam Dergisi, 16(4): 231-234.

Halgin R, Whitbourne S (2006) Abnormal Psychology: Clinical Perspectives on Psychological Disorders. Higher Education 5:216-223.

Howards S, Sudak M (2004) Comprehensive Textbook of Psychiatry. İng. Çev. Aydın ve ark. Güneş Kitabevi, s.24422453.

Kaplan HI, Sadock BJ (2004) Klinik Psikiyatri. İng. Çev. Abay E. Nobel Kitapevi, s.361-367.

Nolen S, Hoeksema N (2004) Abnormal Psychology. Internatıonal Education.4:329-351.

Oktik N, Top A, Sezer S, Bozver U (2003) Muğla İli İntihar ve İntihar Girişimlerinin Sosyolojik Olarak İncelenmesi. Kriz Dergisi, 11(3):11-19.

Sayıl I (2004) Batman İntiharları Giriş. Türkiye Klinikleri Psikiyatri Dergisi, 5(2):73-100. www.die.gov.tr. 